\title{
Numbers Speak Where Words Fail Exploring the Effect of Online Consumer Reviews on Consumer Decision Making
}

\author{
Liu, Albert Fei
}

Document Version

Accepted author manuscript

Published in:

$\mathrm{HCl}$ in Business, Government and Organizations

DOI:

10.1007/978-3-319-58484-3_20

Publication date:

2017

License

Unspecified

Citation for published version (APA):

Liu, A. F. (2017). Numbers Speak Where Words Fail: Exploring the Effect of Online Consumer Reviews on Consumer Decision Making. In F. F-H. Nah, \& C-H. Tan (Eds.), $\mathrm{HCl}$ in Business, Government and Organizations: Supporting Business. Proceedings Part II (Vol. 11, pp. 246-263). Springer. Lecture Notes in Computer Science Vol. 10294 LNCS https://doi.org/10.1007/978-3-319-58484-3_20

Link to publication in CBS Research Portal

\section{General rights}

Copyright and moral rights for the publications made accessible in the public portal are retained by the authors and/or other copyright owners and it is a condition of accessing publications that users recognise and abide by the legal requirements associated with these rights.

Take down policy

If you believe that this document breaches copyright please contact us (research.lib@cbs.dk) providing details, and we will remove access to the work immediately and investigate your claim.

Download date: 26. Apr. 2023
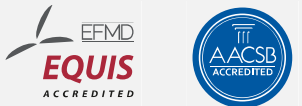


\section{Numbers Speak Where Words Fail: Exploring the Effect of Online Consumer Reviews on Consumer Decision Making} Albert Fei Liu

Article in proceedings (Accepted version*)

\section{Please cite this article as:}

Liu, A. F. (2017). Numbers Speak Where Words Fail: Exploring the Effect of Online Consumer Reviews on Consumer Decision Making. In . F. F-H. Nah, \& C-H. Tan (Eds.), HCI in Business, Government and Organizations: Supporting Business. Proceedings Part II (Vol. 11, pp. 246-263). Cham: Springer. Lecture Notes in Computer Science, Vol.. 10294 LNCS , 00I: 10.1007/978-3-319-58484-3_20

This is a post-peer-review, pre-copyedit version of an article published in HCl in Business, Government and Organizations: Supporting Business. Proceedings Part II. The final authenticated version is available online at:

DOl: https://doi.org/10.1007/978-3-319-58484-3_20

* This version of the article has been accepted for publication and undergone full peer review but has not been through the copyediting, typesetting, pagination and proofreading process, which may lead to differences between this version and the publisher's final version AKA Version of Record. 


\title{
Numbers Speak where Words Fail: Exploring the Effect of Online Consumer Reviews on Consumer Decision Making
}

\author{
Fei Liu ${ }^{1 *}$ \\ ${ }^{1}$ Department of IT Management, Copenhagen Business School, Copenhagen, Denmark \\ afl.itmecbs.dk
}

\begin{abstract}
Consumers are increasingly relying on online consumer reviews (OCRs) to facilitate their decision making process as a credible source of information. This study seeks to explicate why consumers deem OCRs as helpful and how they make use of OCRs in their decision making process. By drawing on Simon's decision making model, this study posits that the two forms of OCRs (i.e., numerical ratings and opinionated reviews) facilitate consumers' decisional processes in terms of the effectiveness of constructing consideration sets and the efficiency of arriving at a final decision. Consumers' performance in decisional process in turn determines the justifiability of and the confidence in their decisional outcomes. To empirically test all the hypotheses proposed in this study, a field survey was conducted on users of a custom-developed online restaurant review website equipped with OCR curation features and populated with real restaurant review data. Except for two unexpected findings, all hypotheses were supported by the data analysis results. It is worth noting that, numerical rating exerts stronger positive influence on decisional process efficiency comparing to opinionated review. Furthermore, decisional outcome justifiability mediates the positive effects of both decisional process effectiveness and decisional process efficiency on decisional outcome confidence. This study contributes to both research and practice by offering a more in depth explanation to consumers' reliance on OCRs through the lens of bounded rationality and providing excitable guidelines for enhancing the benefits of OCRs via curation features.
\end{abstract}

Keywords: Online Consumer Review · Bounded Rationality · Decisional Process $\cdot$ Decisional Outcome $\cdot$ Curation Design

\section{Introduction}

Consumers are increasingly relying on online consumer reviews (OCRs) to facilitate their decision making process [4, 33]. According to Mudambi and Schuff [25], OCRs refer to comments generated by peer consumers on the basis of their evaluation on a pertinent product or service. Recognizing the salient role played by OCRs in steering consumers' purchase decision [29, 40], leading e-commerce sites, such as Amazon, have leveraged on OCRs to assist consumers' product evaluation [20] and to in turn elicit consumers' trust in the sites [37]. The strength of OCRs resides in two aspects.

adfa, p. 1, 2011.

(C) Springer-Verlag Berlin Heidelberg 2011 
First, OCRs supply timely and cost-free information regarding peer-consumers' experience with a product or service $[11,17,38]$. Consequently, approximately $92 \%$ of consumers seek advice from OCRs prior to making purchase decisions [5]. Second, OCRs are deemed more reliable and trustworthy compared to firm-generated information [15]. eMarketer [10] reported that more than $92 \%$ of consumers trust ORCs more than the product description provided by the manufacturers.

Prior literature has corroborated consumers' reliance on OCRs when making purchase intention by substantiating the connection between OCRs and product sales [6, $8,41]$. For instance, Chevalier and Mayzlin [6] uncovered that both review volume and average review rating contribute to boosting book sales. According to Clemons et al. [8], the valence of salient reviews is influential in promoting the sales of newly launched beers. Lastly, Yang and Mai's [41] work revealed that review volume drives up sales of video games due to consumers' tendency to adopt review volume as a heuristic for assessing the quality of a pertinent game. Intrigued by consumers' reliance on OCRs, more recent studies attempted to unravel the underlining characteristics of OCRs that evoke consumers' perceived review helpfulness [25]. Mudambi and Schuff's [25] seminal work gave impetus for this stream of research by exploring how product type moderates the influences of review extremity and review depth on review helpfulness. Subsequent studies extended the range of antecedents of review fullness by incorporating source-relevant characteristics, such as reviewer credibility and reviewer expertise, $[19,31,43]$ in addition to the content-relevant characteristics accentuated by Mudambi and Schuff's [25]. The abovementioned findings are insightful in terms of distinguishing between more helpful OCRs and less helpful ones, yet are insufficient for explicating how OCRs are helpful in consumers' decision making process. This study hence aims to tackle this research gap by elucidating the role of OCRS in consumers' decisional process.

To achieve this research objective, this study subscribes to Simon's bounded rationality paradigm and adopts Simon's decision making model as a theoretical scaffold [35]. Bounded rationality posits that few human decision makers can live up to the substantive rationality assumed by the classical economic model of decision making [26]. Instead of insisting on obtaining the optimal decisional outcome, human decision makers rely on their decisional processes to establish their confidence in their decisional outcomes. This procedural rationality is a compromise made by human decision makers to cope with the constraints posed by their limited time, information, and cognitive capacities [26]. The prominent role of decision justifiability is further corroborated by decision justification theory [9], as justification helps to deter individuals from regretting their decisions. By integrating the paradigm of bounded rationality in the underexplored role of OCRS in consumer decisional process, the following two research questions emerge:

- How do consumers rely on OCRs in their decisional process?

- How do consumers justify their decisional outcomes on the basis of their decisional processes? 
To better answer the abovementioned research questions, this study is situated in the context of online service selection (i.e., online restaurant selection) despite the predominant focus on online product selection in prior literature [42]. Unlike product, service is perishable and its intangible process is experiential in nature [16]. Consequently, the selection process is more complex, contains more ambiguity, and hence renders bounded rationality more salient. This study hence seeks to explicate how bounded rationality manifests in consumers' dependency on OCRs in online service selection process. Guided by Simon's decision making model [35], this study delineates between numerical rating and opinionated review of OCRs as two distinct information sources at the intelligence stage [21, 25]. Subsequently, this study articulates the roles of both forms of OCRs in facilitating the effectiveness of generating alternatives at the design stage and the efficiency of deciding on the most desirable alternative at the choice stage [35]. Last but not least, this study explains the impact of the decisional process on consumers' justifiability of and confidence in their decisional outcome [35].

\section{Bounded Rationality and Decision Making Model}

Simon proposed the paradigm of bounded rationality with the recognition that it is unrealistic to assume substantive rationality for human decision makers [26]. Decision making in the real world setting often involves uncertainties due to missing information [26]. Even with perfect information, limited time and cognitive capacities tend to prevent decision makers from exhausting all possible alternatives and seeking out the optimal outcomes [36]. Instead, human decision makers are governed by procedural rationality, meaning they justify the adequacy of their decisional outcome by their decisional process [26]. Munier et al. [26] applied computer simulations to prove that incorporating bounded rationality in their algorithm can lead to improved decision making performance in terms of accuracy and efficiency when missing information was involved.

With this premise, Simon put forward a model of decision making that consists of three distinct stages: intelligence, design, and choice [35]. At the intelligence stage, decision makers collect information to identify and formulate problems. The design stage resembles the process, in which decision makers devise and evaluate possible solutions to address the problems produced in the intelligence stage. Finally, decision makers arrive at a most satisfactory solution by comparing all possible alternatives against each other in the choice stage. This study subscribes to Simon's decision making model and puts forth a research model that describes how consumers take advantage of OCRs in their decisional processes. This research mode also articulates how consumers leverage on their decisional process to justify their decisional outcomes.

\section{OCRs and Decisional Process}

Numerical rating and opinionated review are two major constituent forms of OCRs [21, 25]. Numerical rating is an ordinal representation of a reviewer's attitude towards a 
product or service. Due to its concise nature, it allows consumers to make swift judgement [12] by facilitating categorical thinking [22]. Opinionated review takes the form of written comments that offer background information and logical reasoning behind a reviewer's assessment. It is cognitively more demanding and leaves room for personal interpretation $[29,30]$. Thereby, on the basis of their examination of a piece of opinionated review, consumers may arrive at a conclusion that differs from the reviewer's opinion. Both numerical rating and opinionated review function as the key information sources in the intelligence stage that convey reviewers' experiences and judgements to consumers [35].

Both forms of OCRs are expected to facilitate consumers' decisional processes in the design stage [35]. The two-stage model of choice making corroborates that decision makers tend to include a sufficient amount of viable alternatives into their consideration set at the design stage before selecting the most satisficing alternative at the choice stage [3]. Decisional process effectiveness refers to the extent to which the decisional process is effective for consumers in evaluating a sufficient number of alternatives. Decisional process effectiveness hence corresponds to the adequacy of a consumer's consideration set at the design stage. On the other hand, decisional process efficiency represents the extent to which consumers are able to economize time and efforts in the decisional process to arrive at the final decision. Therefore, decisional process efficiency is an indicator of the speed with which consumers arrive at the most promising option from their consideration sets in the choice stage.

\subsection{Decisional Process Effectiveness}

The provision of numerical rating and opinionated review can heighten decisional process effectiveness since they allow consumers to identify viable alternatives to be included into their consideration sets. However, because numerical rating is devoid of qualitative attributes, consumers often steer away from viable alternatives due to mediocre ratings without considering the potential fit of their attributes. In contrast, opinionated review contains ample information about various attributes of each alternative, thus encouraging consumers to uncover alternatives that fit their own preferences [29, 30]. Accordingly, opinionated review, in comparison to numerical rating, is more conducive to expanding the variety and coverage of the pool of alternatives [3]. As a result, opinionated review is more beneficial than numerical rating in elevating decisional process effectiveness in the design stage. This study hence hypothesizes:

- Hypothesis 1: The provision of numerical rating positively influences consumers' perceived decisional process effectiveness.

- Hypothesis 2: The provision of opinionated review positively influences consumers' perceived decisional process effectiveness.

- Hypothesis 3: The provision opinionated review exerts a stronger positive influence on consumers' perceived decisional process effectiveness as compared to the provision of numerical rating. 


\subsection{Decisional Process Efficiency}

Consumers' decisional process efficiency in the choice stage can be facilitated by the provision of numerical rating and opinionated review. Both forms of OCRs allow consumers to leverage on reviewers' judgments in order to expedite their comparisons among alternatives. The concise nature of numerical rating is especially suitable for discriminating among alternatives in an efficient manner [12, 25]. In comparison, relying on opinionated review to isolate the most desirable alternative is not as efficient. Specifically, evaluating the rich information available in opinionated review is more cognitively demanding. The increased complexity of considering multiple attributes renders the most desirable option less apparent, thus impeding the facilitating effect of opinionated review on decisional process efficiency in the choice stage. This study hence hypothesizes:

- Hypothesis 4: The provision of numerical rating positively influences consumers' perceived decisional process efficiency.

- Hypothesis 5: The provision of opinionated review positively influences consumers' perceived decisional process efficiency.

- Hypothesis 6: The provision numerical rating exerts a stronger positive influence on consumers' perceived decisional process efficiency as compared to the provision of opinionated review.

\section{Decisional Process and Decisional Outcome}

Consumers' performance in their decisional processes plays a pivotal role in the justification of their decisional outcomes. In accordance with decision justification theory, consumers have to overcome two obstacles to prevent regretting their decisions [9]. In particular, consumers justify their decisions with cognitive evaluations against certain criteria and establish confidence to counter the affective feeling of self-blame [9]. Guided by the bounded rationality paradigm, this study contends that decisional process effectiveness and decisional process efficiency contribute to countering the cognitive and affective components of decisional regret respectively.

\subsection{Decisional Outcome Justifiability}

Decisional outcome justifiability is defined as consumers' awareness of the thoughtful and comprehensive process through which they arrive at their decisions [32]. Prior studies attest to the connection between a carefully conducted decisional process and the decisional outcome justifiability [9, 32]. Conceivably, it is likely for decisional process effectiveness and decisional process efficiency to enhance decisional outcome justifiability. Specifically, decisional process effectiveness helps to bolster the evidential support to the comprehensiveness and accountability of the consideration set. Furthermore, decisional process effectiveness increases the number of counterfactuals that help to legitimize the final choice [32]. On the other hand, decisional process efficiency facilitates consumers' recollection of their heuristics and reasoning for arriving at the final 
choices, thus increasing the likelihood for consumers to regard their selections as intuitive and reasonable. This study hence hypothesizes:

- Hypothesis 7: Consumers' perceived decisional process effectiveness positively influences their perceived decisional outcome justifiability.

- Hypothesis 8: Consumers' perceived decisional process efficiency positively influences their perceived decisional outcome justifiability.

\subsection{Decisional Outcome Confidence}

Decisional outcome confidence captures consumers' feeling that their decisions are correct. The feeling of confidence suppresses the feeling of self-blame, which resembles the affective dimension of decisional regret [9]. Both decisional process effectiveness and decisional process efficiency are expected to strengthen consumers' decisional outcome confidence. For instance, since consumers often draw confidence in their final choices from the size and coverage of their consideration sets, decisional process effectiveness is expected to enhance consumers' decisional outcome confidence. In contrast, decisional process efficiency helps to evoke an impression that the process of arriving at the final decision was simple and straightforward. The resulting underestimation of the complexity of deciding on the most desirable choice can inflate consumers' confidence in their final decisions. This study hence hypothesizes:

- Hypothesis 9: Consumers' perceived decisional process effectiveness positively influences their perceived decisional outcome confidence.

- Hypothesis 10: Consumers' perceived decisional process efficiency positively influences their perceived decisional outcome confidence.

By conducting four consecutive experiments, Reb and Connelly [32] confirmed that decisional outcome justifiability can preemptively mitigate the likelihood of decision makers to regret their decisions. Along the same vein, decisional outcome justifiability can help to relieve consumers from the anxiety of being responsible for making undesirable decisions. Consequently, it is more likely for consumers to feel confident about their decisions when perceiving higher decisional outcome justifiability. This study hence hypothesizes:

- Hypothesis 11: Consumers' perceived decisional outcome justifiability positively influences their perceived decisional outcome confidence.

\section{$5 \quad$ Methodology}

To empirically validate the hypotheses proposed by this study, a field survey was conducted on a custom-developed online restaurant review site. To ensure the realism of this custom-developed site, its design was emulated after that of a leading online restaurant review sites, it is also populated with a real dataset that contains detailed descriptions of 1,079 restaurants in the San Francisco region together with about 268,000 
reviews for these restaurants written by roughly 91,000 diners. Two OCR curation features are implemented for each restaurant to display both numerical ratings and opinionated reviews. The numerical rating curation feature depicts a histogram of the distribution of ratings as well as a trend line for the variation of average rating throughout the time. The opinionated review curation feature resembles a word cloud that summarizes the most prominent keywords in reviewers' written comments. This custom-developed site encourages participants to employ both forms of OCRs in their decisional processes and to facilitate the recollection of their decision making experience when answering the questionnaire.

\subsection{Development of Survey Measures}

Measurement items for numerical rating, opinionated review, decisional process effectiveness, and decisional process efficiency were newly developed in accordance with established psychometric procedures [24]. The measures for decisional outcome justifiability and decisional outcome confidence were developed by extending existing instruments [32]. Table 1 summarizes all measurement instruments developed for this study.

Table 1. Instrument and Measurement Properties for Reflective Measures [Sample N = 170]

\begin{tabular}{|c|c|c|c|c|}
\hline Construct & Definition & $\begin{array}{l}\text { Reflective Measures [7-point Likert } \\
\text { scale] }\end{array}$ & $\begin{array}{l}\text { Mean } \\
\text { (S.D.) }\end{array}$ & $\begin{array}{c}\text { Item } \\
\text { Loading }\end{array}$ \\
\hline \multirow{3}{*}{$\begin{array}{l}\text { Numerical } \\
\text { Rating (NR) }\end{array}$} & \multirow{3}{*}{$\begin{array}{l}\text { Extent to which } \\
\text { a consumer be- } \\
\text { lieves that nu- } \\
\text { merical ratings } \\
\text { are provided for } \\
\text { each product or } \\
\text { service featured } \\
\text { on the online re- } \\
\text { view website }\end{array}$} & $\begin{array}{l}\text { The online review website provides numer- } \\
\text { ical ratings assigned by other consumers for } \\
\text { each restaurant featured on the site. }\end{array}$ & $\begin{array}{c}5.65 \\
(1.27)\end{array}$ & 0.82 \\
\hline & & $\begin{array}{l}\text { The online review website provides numer- } \\
\text { ical scores assigned by other consumers for } \\
\text { each restaurant featured on the site. }\end{array}$ & $\begin{array}{c}5.26 \\
(1.44)\end{array}$ & 0.92 \\
\hline & & $\begin{array}{l}\text { The online review website provides numer- } \\
\text { ical values assigned by other consumers for } \\
\text { each restaurant featured on the site. }\end{array}$ & $\begin{array}{c}5.20 \\
(1.45)\end{array}$ & 0.87 \\
\hline \multirow{3}{*}{$\begin{array}{l}\text { Opinionated } \\
\text { Review } \\
(\text { OR) }\end{array}$} & \multirow{3}{*}{$\begin{array}{l}\text { Extent to which } \\
\text { a consumer be- } \\
\text { lieves that opin- } \\
\text { ionated reviews } \\
\text { are provided for } \\
\text { each product or } \\
\text { service featured } \\
\text { on the online re- } \\
\text { view website }\end{array}$} & $\begin{array}{l}\text { The online review website provides other } \\
\text { consumers comments for each restaurant } \\
\text { featured on the site. }\end{array}$ & $\begin{array}{c}6.02 \\
(1.16)\end{array}$ & 0.85 \\
\hline & & $\begin{array}{l}\text { The online review website provides other } \\
\text { consumers' feedback for each restaurant } \\
\text { featured on the site. }\end{array}$ & $\begin{array}{c}5.93 \\
(1.10)\end{array}$ & 0.86 \\
\hline & & $\begin{array}{l}\text { The online review website provides other } \\
\text { consumers' impressions for each restaurant } \\
\text { featured on the site. }\end{array}$ & $\begin{array}{c}5.95 \\
(1.10)\end{array}$ & 0.90 \\
\hline
\end{tabular}




\begin{tabular}{|c|c|c|c|c|}
\hline & & $\begin{array}{l}\text { The online review website provides other } \\
\text { consumers opinions for each restaurant } \\
\text { featured on the site. }\end{array}$ & $\begin{array}{c}5.90 \\
(1.15)\end{array}$ & 0.93 \\
\hline & & $\begin{array}{l}\text { The online review website provides other } \\
\text { consumers' views for each restaurant fea- } \\
\text { tured on the site. }\end{array}$ & $\begin{array}{c}5.92 \\
(1.12)\end{array}$ & 0.90 \\
\hline \multirow{3}{*}{$\begin{array}{l}\text { Decisional } \\
\text { Process Ef- } \\
\text { fectiveness } \\
\text { (PE) }\end{array}$} & \multirow{3}{*}{$\begin{array}{l}\text { Extent to which } \\
\text { the decisiona } \\
\text { process is effec } \\
\text { tive for consum- } \\
\text { ers in evaluating } \\
\text { a sufficient num } \\
\text { ber of alterna- } \\
\text { tives }\end{array}$} & $\begin{array}{l}\text { Reviews provided via the online review web- } \\
\text { site allow me to assess an acceptable num- } \\
\text { ber of restaurants when deciding on which } \\
\text { restaurant to visit. }\end{array}$ & $\begin{array}{c}5.56 \\
(1.21)\end{array}$ & 0.96 \\
\hline & & $\begin{array}{l}\text { Reviews provided via the online review web- } \\
\text { site allow me to evaluate an appropriate } \\
\text { number of restaurants when deciding on } \\
\text { which restaurant to visit. }\end{array}$ & $\begin{array}{c}5.48 \\
(1.18)\end{array}$ & 0.95 \\
\hline & & $\begin{array}{l}\text { Reviews provided via the online review web- } \\
\text { site allow me to go through a reasonable } \\
\text { number of restaurants when deciding on } \\
\text { which restaurant to visit. }\end{array}$ & $\begin{array}{c}5.54 \\
(1.17)\end{array}$ & 0.95 \\
\hline \multirow{4}{*}{$\begin{array}{l}\text { Decisional } \\
\text { Process Effi- } \\
\text { ciency (PI) }\end{array}$} & \multirow{4}{*}{$\begin{array}{l}\text { Extent to which } \\
\text { consumers ex- } \\
\text { pend less time } \\
\text { and efforts in the } \\
\text { decisional pro- } \\
\text { cess to arrive at } \\
\text { the final decision }\end{array}$} & $\begin{array}{l}\text { The process of deciding on which restaurant } \\
\text { to visit is efficient based on reviews pro- } \\
\text { vided via the online review website. }\end{array}$ & $\begin{array}{c}5.32 \\
(1.36)\end{array}$ & 0.88 \\
\hline & & $\begin{array}{l}\text { The process of deciding on which restaurant } \\
\text { to visit is fast based on reviews provided via } \\
\text { the online review website. }\end{array}$ & $\begin{array}{c}5.12 \\
(1.49)\end{array}$ & 0.94 \\
\hline & & $\begin{array}{l}\text { The process of deciding on which restaurant } \\
\text { to visit is free of hassle based on reviews } \\
\text { provided via the online review website. }\end{array}$ & $\begin{array}{c}4.94 \\
(1.50)\end{array}$ & 0.91 \\
\hline & & $\begin{array}{l}\text { The process of deciding on which restaurant } \\
\text { to visit is effortless based on reviews pro- } \\
\text { vided via the online review website. }\end{array}$ & $\begin{array}{c}4.75 \\
(1.50)\end{array}$ & 0.91 \\
\hline \multirow{3}{*}{$\begin{array}{l}\text { Decisional } \\
\text { Outcome } \\
\text { Justifiability } \\
\text { (OJ) }\end{array}$} & \multirow{3}{*}{$\begin{array}{l}\text { Extent to which } \\
\text { consumers are } \\
\text { aware of the } \\
\text { thoughtful and } \\
\text { comprehensive } \\
\text { process through } \\
\text { which they ar- } \\
\text { rive at their deci- } \\
\text { sions }\end{array}$} & $\begin{array}{l}\text { I am clear about how I arrive at my decision } \\
\text { about which restaurant to visit based on re- } \\
\text { views provided via the online review web- } \\
\text { site. }\end{array}$ & $\begin{array}{c}5.60 \\
(1.14)\end{array}$ & 0.92 \\
\hline & & $\begin{array}{l}\text { I can explain to others how I arrive at my } \\
\text { decision about which restaurant to visit } \\
\text { based on reviews provided via the online re- } \\
\text { view website. }\end{array}$ & $\begin{array}{c}5.55 \\
(1.32)\end{array}$ & 0.94 \\
\hline & & $\begin{array}{l}\text { I can justify to others how I arrive at my de- } \\
\text { cision about which restaurant to visit based } \\
\text { on reviews provided via the online review } \\
\text { website. }\end{array}$ & $\begin{array}{c}5.59 \\
(1.20)\end{array}$ & 0.95 \\
\hline
\end{tabular}




\begin{tabular}{|c|c|c|c|c|}
\hline & & $\begin{array}{l}\text { I can understand how I arrive at my deci- } \\
\text { sion about which restaurant to visit based on } \\
\text { reviews provided via the online review web- } \\
\text { site. }\end{array}$ & $\begin{array}{c}5.65 \\
(1.21)\end{array}$ & 0.95 \\
\hline \multirow{3}{*}{$\begin{array}{l}\text { Decisional } \\
\text { Outcome } \\
\text { Confidence } \\
\text { (OC) }\end{array}$} & \multirow{3}{*}{$\begin{array}{l}\text { Extent to which } \\
\text { consumers feel } \\
\text { that their deci- } \\
\text { sions are correct }\end{array}$} & $\begin{array}{l}\text { I am certain that I have made the right de- } \\
\text { cision about which restaurant to visit based } \\
\text { on reviews provided via the online review } \\
\text { website. }\end{array}$ & $\begin{array}{c}5.04 \\
(1.40)\end{array}$ & 0.94 \\
\hline & & $\begin{array}{l}\text { I am confident that I have made the right } \\
\text { decision about which restaurant to visit } \\
\text { based on reviews provided via the online re- } \\
\text { view website. }\end{array}$ & $\begin{array}{c}5.04 \\
(1.42)\end{array}$ & 0.97 \\
\hline & & $\begin{array}{l}\text { I am sure that I have made the right decision } \\
\text { about which restaurant to visit based on re- } \\
\text { views provided via the online review web- } \\
\text { site. }\end{array}$ & $\begin{array}{c}4.96 \\
(1.43)\end{array}$ & 0.96 \\
\hline
\end{tabular}

\subsection{Field Survey Administration}

At the beginning of each survey session, respondents were asked to report their demographic backgrounds. They were then directed to the online review website and instructed to conduct two restaurant selection tasks. The first task is goal-oriented and respondents were offered well-structured criteria for the targeted restaurants whereas the second task is exploratory hence granting respondents the freedom to select a restaurant according to their own preference [2,27]. The scenarios of both tasks are presented in Table 2. Respondents were asked to make their decisions basing on the $n u$ merical ratings and opinionated reviews curated for each restaurant. Upon the completion of both tasks, respondents were brought back to an online survey questionnaire that measures their dispositions pertaining to the provision of numerical rating and opinionated review, the effectiveness and efficiency of their decisional processes, as well as the justifiability of and confidence in their decisional outcomes. 170 undergraduate students from a large university in the United States were recruited for this field survey. The demographics of this sample are presented in Table 3.

Table 2. Restaurant Selection Tasks

\section{Task 1: Find a restaurant for your friend's birthday dinner}

Scenario: You are planning to visit your best friend, Peter, who lives in the Russian Hillarea of San Francisco and likes New American food, next Saturday. Peter will be having his birthday on the same day. You plan to surprise Peter during your visit by bringing him to a nice New American restaurant to celebrate his birthday. 
Because you are unfamiliar with the area around Russian Hill, you decide to turn to TasteSF, a newly set up online review website for restaurants in San Francisco, to choose an American (NEW) restaurant in the Russian Hill area.

\section{Task 2: Find a restaurant for yourself}

You are taking a trip to San Francisco next Saturday. You would like to enjoy a meal alone in a nice restaurant. Because you are unfamiliar with San Francisco, you decide to turn to TasteSF, a newly set up online review website for restaurants in San Francisco, to choose a restaurant you prefer.

\subsection{Model Testing}

This study evaluated both the measurement model and the structural model by employing Partial Least Square (SmartPLS 2.0 M3) [7]. Partial least squares (PLS) analysis is more preferable than other analytical methods since this study seeks to simultaneously analyze the psychometric properties of the measures (i.e., the measurement model) as well as the coefficients of the hypothesized nomological network (i.e., the structural model) [39].

Table 3. Sample Demographics [Sample N = 170]

\begin{tabular}{|c|c|c|c|}
\hline \multicolumn{2}{|r|}{ Demographic } & No. Respondents & Percentage \\
\hline \multirow{2}{*}{ 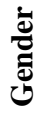 } & Male & 88 & $51.8 \%$ \\
\hline & Female & 82 & $48.2 \%$ \\
\hline \multirow{4}{*}{$\underset{8}{8}$} & Age 12 to 18 & 3 & $1.8 \%$ \\
\hline & Age 19 to 29 & 153 & $90.0 \%$ \\
\hline & Age 30 to 49 & 13 & $7.6 \%$ \\
\hline & Age $60+$ & 1 & $0.6 \%$ \\
\hline \multirow{3}{*}{ : } & Less than college education & 20 & $11.8 \%$ \\
\hline & College education or higher & 149 & $87.6 \%$ \\
\hline & Unwilling to disclose & 1 & $0.6 \%$ \\
\hline \multirow{5}{*}{$\begin{array}{l}\text { : } \\
\text { : } \\
\text { : }\end{array}$} & $\$ 0$ to $\$ 30,000$ & 140 & $82.4 \%$ \\
\hline & $\$ 30,000+$ to $\$ 50,000$ & 9 & $5.3 \%$ \\
\hline & $\$ 50,000+$ to $\$ 75,000$ & 4 & $2.4 \%$ \\
\hline & $\$ 75,000+$ & 2 & $1.2 \%$ \\
\hline & Unwilling to disclose & 15 & $8.8 \%$ \\
\hline
\end{tabular}

Measurement Model. This study assessed the measurement model by evaluating internal consistency, as well as the convergent and discriminant validity of all focal constructs in our survey instrument. To ensure internal consistency, the reliability of each 
individual measurement item was examined by its loading on the corresponding construct. As shown in Table 1, all loadings exceed 0.7, indicating good item reliability. Additionally, construct reliability indexes, including Cronbach's alpha, composite reliability and the Average Variance Extracted (AVE) were assessed [13, 28]. Results illustrated in Table 4 indicate that all aforementioned indictors exceed suggested thresholds, suggesting good internal consistency. Subsequently, the square root of AVE of every construct in the measurement model was found to be greater than the correlations of each construct with other constructs (see Table 4). Furthermore, according to the loading and cross-loading matrix depicted in Table 5, no measurement item loads higher on a construct than on the one it intends to measure. Therefore, the results presented above resemble strong evidences of convergent validity and discriminate validity.

Table 4. Internal Consistencies and Inter-Construct Correlation Matrix [Sample N = 170]

\begin{tabular}{|c|c|c|c|c|c|c|c|c|c|}
\hline Construct & \begin{tabular}{|c|} 
Cronbach's \\
$\alpha[>0.70]$
\end{tabular} & $\begin{array}{c}\mathrm{CR} \\
{[>0.70]}\end{array}$ & $\begin{array}{c}\mathrm{AVE} \\
{[>0.50]}\end{array}$ & NR & OR & $\mathbf{P E}$ & PI & OJ & OC \\
\hline Numerical Rating (NR) & 0.84 & 0.90 & 0.76 & 0.87 & & & & & \\
\hline $\begin{array}{l}\text { Opinionated Review } \\
\text { (OR) }\end{array}$ & 0.93 & 0.95 & 0.79 & 0.44 & 0.89 & & & & \\
\hline $\begin{array}{l}\text { Decisional Process Ef- } \\
\text { fectiveness (PE) }\end{array}$ & 0.95 & 0.97 & 0.91 & 0.31 & 0.31 & 0.95 & & & \\
\hline $\begin{array}{l}\text { Decisional Process Effi- } \\
\text { ciency (PI) }\end{array}$ & 0.93 & 0.95 & 0.83 & 0.42 & 0.31 & 0.64 & 0.91 & & \\
\hline $\begin{array}{l}\text { Decisional Outcome } \\
\text { Justifiability (OJ) }\end{array}$ & 0.96 & 0.97 & 0.88 & 0.22 & 0.37 & 0.52 & 0.61 & 0.94 & \\
\hline $\begin{array}{l}\text { Decisional Outcome } \\
\text { Confidence (OC) }\end{array}$ & 0.96 & 0.97 & 0.92 & 0.28 & 0.23 & 0.50 & 0.70 & 0.66 & 0.96 \\
\hline
\end{tabular}

Table 5. Loading and Cross-Loading Matrix [Sample $\mathrm{N}=170$ ]

\begin{tabular}{|c|c|c|c|c|c|c|}
\hline Items & NR & OR & DPE & DPI & DOJ & DOC \\
\hline NR1 & $\mathbf{0 . 8 2}$ & 0.49 & 0.35 & 0.36 & 0.25 & 0.23 \\
\hline NR2 & $\mathbf{0 . 9 2}$ & 0.32 & 0.25 & 0.34 & 0.15 & 0.27 \\
\hline NR3 & $\mathbf{0 . 8 7}$ & 0.32 & 0.20 & 0.40 & 0.16 & 0.22 \\
\hline OR1 & 0.45 & $\mathbf{0 . 8 5}$ & 0.25 & 0.22 & 0.25 & 0.16 \\
\hline OR2 & 0.39 & $\mathbf{0 . 8 6}$ & 0.23 & 0.27 & 0.28 & 0.17 \\
\hline OR3 & 0.39 & $\mathbf{0 . 9 0}$ & 0.27 & 0.27 & 0.35 & 0.21 \\
\hline OR4 & 0.36 & $\mathbf{0 . 9 3}$ & 0.29 & 0.29 & 0.38 & 0.23 \\
\hline OR5 & 0.38 & $\mathbf{0 . 9 0}$ & 0.31 & 0.33 & 0.37 & 0.23 \\
\hline DPE1 & 0.35 & 0.29 & $\mathbf{0 . 9 6}$ & 0.64 & 0.48 & 0.48 \\
\hline
\end{tabular}




\begin{tabular}{|l|l|l|l|l|l|l|}
\hline DPE2 & 0.27 & 0.30 & $\mathbf{0 . 9 5}$ & 0.61 & 0.51 & 0.51 \\
\hline DPE3 & 0.28 & 0.29 & $\mathbf{0 . 9 5}$ & 0.59 & 0.50 & 0.44 \\
\hline DPI1 & 0.38 & 0.31 & 0.66 & $\mathbf{0 . 8 8}$ & 0.60 & 0.61 \\
\hline DPI2 & 0.39 & 0.32 & 0.62 & $\mathbf{0 . 9 4}$ & 0.61 & 0.65 \\
\hline DPI3 & 0.36 & 0.27 & 0.56 & $\mathbf{0 . 9 1}$ & 0.49 & 0.65 \\
\hline DPI4 & 0.42 & 0.23 & 0.50 & $\mathbf{0 . 9 0}$ & 0.50 & 0.64 \\
\hline DOJ1 & 0.25 & 0.35 & 0.54 & 0.63 & $\mathbf{0 . 9 2}$ & 0.65 \\
\hline DOJ2 & 0.19 & 0.32 & 0.44 & 0.57 & $\mathbf{0 . 9 4}$ & 0.61 \\
\hline DOJ3 & 0.20 & 0.35 & 0.49 & 0.54 & $\mathbf{0 . 9 5}$ & 0.61 \\
\hline DOJ4 & 0.19 & 0.38 & 0.48 & 0.54 & $\mathbf{0 . 9 5}$ & 0.61 \\
\hline DOC1 & 0.28 & 0.21 & 0.46 & 0.65 & 0.59 & $\mathbf{0 . 9 4}$ \\
\hline DOC2 & 0.27 & 0.23 & 0.49 & 0.68 & 0.65 & $\mathbf{0 . 9 7}$ \\
\hline DOC3 & 0.25 & 0.21 & 0.49 & 0.69 & 0.66 & $\mathbf{0 . 9 6}$ \\
\hline
\end{tabular}

Structural Model. The nomological network of the structure model is illustrated in Figure 1. The estimated coefficients substantiate the positive relationships between $n u$ merical rating $\left(\beta_{1}=0.220, t=4.866\right)$ as well as opinionated review $\left(\beta_{2}=0.210, t=\right.$ 4.582 ) and decisional process effectiveness, hence supporting Hypothesis 1 and 2 . Likewise, the positive influences induced by numerical rating $\left(\beta_{4}=0.354, t=6.489\right)$ and opinionated review $\left(\beta_{5}=0.156, t=3.094\right)$ are validated, thus supporting Hypothesis 4 and 5. Hypothesis 7 and 8 are supported because both decisional process effectiveness $\left(\beta_{7}=0.220, t=3.513\right)$ and decisional process efficiency $\left(\beta_{8}=0.466, t=7.449\right)$ pose positive effects on decisional outcome justifiability. Decisional process efficiency $\left(\beta_{10}\right.$ $=0.473, t=9.025)$ also exerts positive influence on decisional outcome confidence whereas decisional process effectiveness $\left(\beta_{9}=0.003, t=0.096\right)$ does not, therefore only supporting Hypothesis 10. Lastly, Hypothesis 11 is supported by the significant positive relationship between decisional outcome justifiability and decisional outcome confidence $\left(\beta_{11}=0.374, t=6.993\right)$. The unsupported Hypothesis 9 implies that eliciting a sufficient number of alternatives in the consideration set does not ensure consumers' confidence in their final choices. 


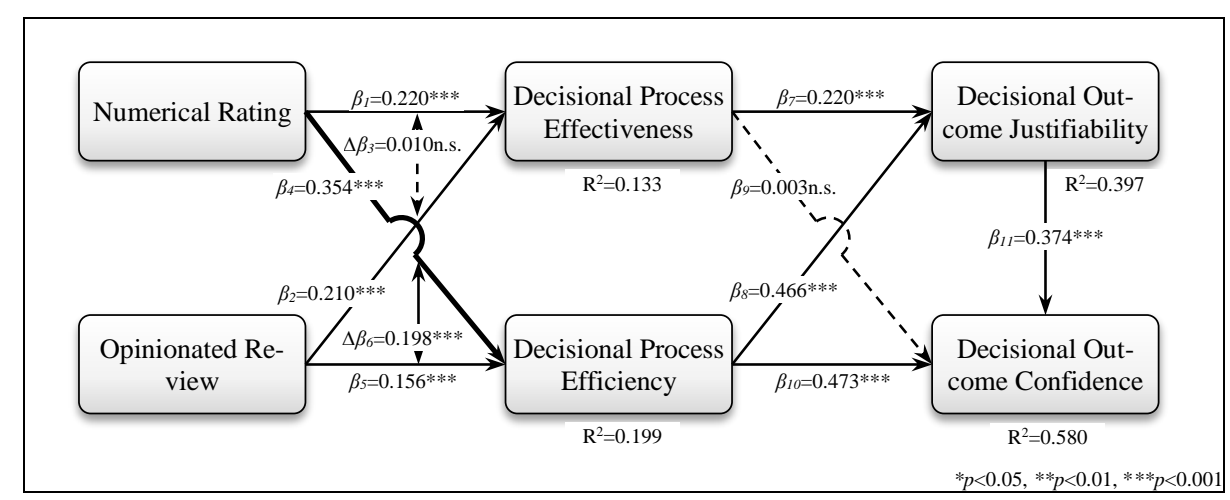

Fig. 1. The Resulting Structural Model $[N=170]$

With regard to the comparative hypotheses, Hypothesis 3 is not supported since the path coefficient between numerical rating and decisional process effectiveness does not differ significantly from that between opinionated review and decisional process effectiveness $(\Delta \beta 3=0.010, t=0.227)$. Surprisingly, numerical rating contributes equally to boosting decisional process effectiveness probably because it helps consumers to exclude undesirable alternatives from their consideration sets [18, 37]. Nonetheless, Hypothesis 6 is supported by the significant difference between the positive effect imposed by numerical rating and that imposed by opinionated review on decisional process efficiency $(\triangle \beta 6=0.198, \mathrm{t}=3.841)$.

Because the dataset in this study was collected via a single survey questionnaire, common method bias could be a potential threat to the internal validity of this study. To mitigate the concern for common method bias, this study conducted the one-factor extraction test [14] by performing exploratory factor analysis (EFA) on 22 variables. Five salient components with eigenvalues greater than 1.00 were extracted with no single factor accounting for more than 50\% of the total variance explained [34], suggesting that it is unlikely for common method bias to erode the validity of data analysis results in this study.

Mediation Analysis. Following standard guidelines [1], mediation analysis was performed to evaluate all mediating effects existing in the nomological network. Table 6 summarizes the results of mediation analysis. For a mediating effect to hold, coefficients in the independent paths column must be significant. Moreover, when the path from IV to the mediator as well as the path from the mediator to the dependent variable (DV) are controlled, the path coefficient from IV to DV should decrease in both magnitude and significance [1]. If the path coefficient from IV to DV becomes non-significant, the mediating effect can be interpreted as a full mediation. Otherwise, it should be interpreted as a partial mediation. The results in Table 6 illustrate that both decisional process effectiveness and decisional process efficiency fully mediate the positive influence of numerical rating but partially mediate that of opinionated review on decisional outcome justifiability. The unexpected direct impact of opinionated review on decisional outcome justifiability can be explained by the reasoning and logics available in 
written comments, which offer extra means for consumers to justify their final selections. Decisional process efficiency fully mediates the positive effects induced by both numerical rating and opinionated review on decisional outcome confidence. Finally, decisional outcome justifiability fully mediates the positive relationship between decisional process effectiveness and decisional outcome confidence.

Table 6. Results of Mediation Analysis

\begin{tabular}{|c|c|c|c|c|c|}
\hline \multirow[b]{2}{*}{ Relationship } & \multicolumn{2}{|c|}{ IV: NR } & \multirow[b]{2}{*}{ Relationship } & \multicolumn{2}{|c|}{ IV: OR } \\
\hline & $\begin{array}{c}\text { Independent } \\
\text { Paths }\end{array}$ & Full Model & & $\begin{array}{c}\text { Independent } \\
\text { Paths }\end{array}$ & Full Model \\
\hline $\mathrm{NR} \rightarrow \mathrm{PE}$ & $0.220 * * *$ & $0.220 * * *$ & $\mathrm{OR} \rightarrow \mathrm{PE}$ & $0.210 * * *$ & $0.210 * * *$ \\
\hline $\mathrm{PE} \rightarrow \mathrm{OJ}$ & $0.220 * * *$ & $0.223 * * *$ & $\mathrm{PE} \rightarrow \mathrm{OJ}$ & $0.220 * * *$ & $0.187 * * *$ \\
\hline $\mathrm{NR} \rightarrow \mathrm{OJ}$ & $0.220 * * *$ & -0.057 n.s. & $\mathrm{OR} \rightarrow \mathrm{OJ}$ & $0.377 * * *$ & $0.183 * * *$ \\
\hline \multicolumn{3}{|c|}{ Full Mediation } & \multicolumn{3}{|c|}{ Partial Mediation } \\
\hline $\mathrm{PE} \rightarrow \mathrm{OC}$ & 0.003 n.s. & 0.003 n.s. & $\mathrm{PE} \rightarrow \mathrm{OC}$ & 0.003 n.s. & 0.011 n.s. \\
\hline $\mathrm{NR} \rightarrow \mathrm{OC}$ & $0.280 * * *$ & -0.005 n.s. & $\mathrm{OR} \rightarrow \mathrm{OC}$ & $0.229 * * *$ & -0.072 n.s. \\
\hline \multicolumn{3}{|c|}{ No Mediation } & \multicolumn{3}{|c|}{ No Mediation } \\
\hline $\mathrm{NR} \rightarrow \mathrm{PI}$ & $0.354 * * *$ & $0.353 * * *$ & $\mathrm{OR} \rightarrow \mathrm{PI}$ & $0.156^{* * *}$ & $0.157 * * *$ \\
\hline $\mathrm{PI} \rightarrow \mathrm{OJ}$ & $0.466 * * *$ & $0.488 * * *$ & $\mathrm{PI} \rightarrow \mathrm{OJ}$ & $0.466 * * *$ & $0.430 * * *$ \\
\hline $\mathrm{NR} \rightarrow \mathrm{OJ}$ & $0.220 * * *$ & -0.057 n.s. & $\mathrm{OR} \rightarrow \mathrm{OJ}$ & $0.377 * * *$ & $0.183 * * *$ \\
\hline \multicolumn{3}{|c|}{ Full Mediation } & \multicolumn{3}{|c|}{ Partial Mediation } \\
\hline $\mathrm{PI} \rightarrow \mathrm{OC}$ & $0.473 * * *$ & $0.475 * * *$ & $\mathrm{PI} \rightarrow \mathrm{OC}$ & $0.473 * * *$ & $0.478 * * *$ \\
\hline $\mathrm{NR} \rightarrow \mathrm{OC}$ & $0.280 * * *$ & -0.005 n.s. & $\mathrm{OR} \rightarrow \mathrm{OC}$ & $0.229 * * *$ & -0.072 n.s. \\
\hline \multicolumn{3}{|c|}{ Full Mediation } & \multicolumn{3}{|c|}{ Full Mediation } \\
\hline \multirow[b]{2}{*}{ Relationship } & \multicolumn{2}{|c|}{ IV: PE } & \multirow{6}{*}{\multicolumn{3}{|c|}{$\begin{array}{l}\text { Note: IV: Independent Variable, NR: Nu- } \\
\text { merical Rating, OR: Opinionated Review, PE: } \\
\text { Decisional Process Effectiveness, PI: Deci- } \\
\text { sional Process Efficiency, OJ: Decisional Out- } \\
\text { come Justifiability, OC: Decisional Outcome } \\
\text { Confidence. }\end{array}$}} \\
\hline & $\begin{array}{c}\text { Independent } \\
\text { Paths }\end{array}$ & Full Model & & & \\
\hline $\mathrm{PE} \rightarrow \mathrm{OJ}$ & $0.216 * * *$ & $0.220 * * *$ & & & \\
\hline $\mathrm{OJ} \rightarrow \mathrm{OC}$ & $0.374 * * *$ & $0.374 * * *$ & & & \\
\hline $\mathrm{PE} \rightarrow \mathrm{OC}$ & $0.501 * * *$ & 0.003 n.s. & & & \\
\hline \multicolumn{3}{|c|}{ Full Mediation } & & & \\
\hline
\end{tabular}

\section{Discussion}

Adhering to the bounded rationality paradigm and Simon's decision making model [35], this study advances a research model to explicate how consumers take advantage of OCRs in their decision making process. Empirical evidence proves that curating both numerical and textual components of OCRs can improve both the effectiveness regarding eliciting an adequate consideration set and the efficiency in terms of deciding on the most desirable option of consumers' decisional processes. Moreover, results show that both decisional process effectiveness and decisional process efficiency help consumers 
to justify their decisional outcomes which in turn strengthens the consumers' confidence in their own decisions. Results did not establish a connection between decisional process efficiency and decisional outcome confidence. This study hence identifies consumers' procedural rationality as the key to their reliance on OCRs when evaluating and selecting services online [26].

\subsection{Implications for Research}

This study seeks to contribute to extant literature in OCRs on multiple fronts. First, this study is among the first that examines consumers' reliance on OCRs from the perspective of Simon's decision making model [35]. This theoretical lens compels this study to unravel the role played by OCRs in facilitating consumers' decision making process, and to help them in justifying the adequacy of the decisional outcome. Second, this study delineates between the numerical rating and opinionated review of OCRs and uncovers their distinct effects on consumers' decision making process. In particular, numerical rating prevents consumers from including undesirable alternatives into their consideration sets $[18,37]$ whereas opinionated review allows users to extend the size and diversity of their consideration sets by supplying rich information. Additionally, numerical rating, as compared to opinioned review, is more effective in expediting the process of arriving at the most desirable option in the pool of viable alternatives while the latter can pose direct impact on consumers' decisional outcome justifiability by exposing them to reviewers' reasoning and arguments. Third, this study helps to decipher how consumers depend on their decisional process to justify their decisional outcomes and to develop confidence in their decisions. Governed by procedure rationality, consumers would justify their decisional outcomes by drawing upon decisional process effectiveness, which indicates whether a sufficient amount of alternatives was included in the consideration set, and decisional process efficiency, which reflects whether the process of making the final choice was intuitive and reasonable. In line with decision justification theory [9], consumers derive confidence in their decisional outcomes from decisional outcome justifiability. However, the positive relationship between decisional process efficiency and decisional outcome confidence implies that consumers are likely to perceive a decision to be less difficult and are thus more confident in their decisions, if the decision making process was quick and effortless.

\subsection{Implications for Practice}

Practitioners who seek to make use of OCRs can also derive implications from the findings of this study. First, this study helps to draw practitioners' attention to one of the main values of OCRs, which is to help consumers justify their decisions. Consequently, this study encourages practitioners to better utilize OCRs to reassure consumers of their decisions. Second, this study can serve as an example in the employment of curation features to boost the benefits of OCRs with the objective of facilitating consumers' decision making process. For instance, numerical rating curation features can be implemented to highlight the underlining patterns in reviewers' ratings in the forms of histograms and trend lines. In addition, opinionated review curation features can be 
designed to extract recurring themes and sentiments from reviewers' written comments and present them in the form of review highlights or word clouds. This study further suggests that practitioners should prioritize curating numerical ratings over opinionated reviews as the former is more effective, as compared to the latter, in heightening decisional process efficiency while offering comparable utility in facilitating decisional process effectiveness.

\subsection{Limitations and Future Research Directions}

This study faces a number of limitations. First, the empirical investigation of this study was situated in the context of an online service selection. Due to the prevalent uncertainty in online service evaluation, such a context is more preferable for investigating consumer' bounded rationality. Nonetheless, caution should be exercised when generalizing the findings in this study to the context of online product selection. Second, the sample of this study comprises largely of undergraduate students. Although student sample is adequate for studying phenomena pertaining to the use of OCRs [23], future studies can bolster their external validity by utilizing a more diverse sample. Third, spurious causality inferences may exist due to the cross-sectional nature of field survey, which is the main research method of this study.

\section{$7 \quad$ References}

1. Baron, R.M., Kenny, D.A.: The moderator-mediator variable distinction in social psychological research: Conceptual, strategic, and statistical considerations. J. Pers. Soc. Psychol. 51, 6, 1173 (1986).

2. Browne, G.J. et al.: Cognitive stopping rules for terminating information search in online tasks. MIS Q. 31, 1, 89-104 (2007).

3. Browne, G.J., Pitts, M.G.: Stopping rule use during information search in design problems. Organ. Behav. Hum. Decis. Process. 95, 2, 208-224 (2004).

4. Cao, Q. et al.: Exploring determinants of voting for the "helpfulness" of online user reviews: A text mining approach. Decis. Support Syst. 50, 2, 511-521 (2011).

5. ChannelAdvisor: Through the Eyes of the Consumer: 2010 Consumer Shopping Habits Survey. (2010).

6. Chevalier, J.A., Mayzlin, D.: The effect of word of mouth on sales: Online book reviews. J. Mark. Res. 43, 3, 345-354 (2006).

7. Chin, W.W.: Commentary: Issues and opinion on structural equation modeling, (1998).

8. Clemons, E.K. et al.: When online reviews meet hyperdifferentiation: A study of the craft beer industry. J. Manag. Inf. Syst. 23, 2, 149-171 (2006).

9. Connolly, T., Zeelenberg, M.: Regret in decision making. Curr. Dir. Psychol. Sci. 11, 6, 212-216 (2002).

10. eMarketer: Moms Place Trust in Other Consumers, http://www.emarketer.com/Article/Moms-Place-Trust-Other-Consumers/1007509.

11. Ertimur, B., Gilly, M.C.: So whaddya think? Consumers create ads and other consumers critique them. J. Interact. Mark. 26, 3, 115-130 (2012).

12. Fiske, S.T., Taylor, S.E.: Social cognition: From brains to culture. Sage (2013). 
13. Fornell, C., Larcker, D.F.: Evaluating structural equation models with unobservable variables and measurement error. J. Mark. Res. 18, 1, 39-50 (1981).

14. Harman, H.H.: Modern factor analysis. University of Chicago Press (1976).

15. Jabr, W., Zheng, E.: Know yourself and know your enemy: An analysis of firm recommendations and consumer reviews in a competitive environment. Jabr, Wael Eric Zheng." Know Yours. Know Your Enemy An Anal. Firm Recomm. Consum. Rev. a Compet. Environ. MIS Quarterly. Accept. July. (2013).

16. Kahn, B.K. et al.: Information quality benchmarks: Product and service performance. Commun. ACM. 45, 4, 184-192 (2002).

17. Lawrence, B. et al.: When companies don't make the ad: A multimethod inquiry into the differential effectiveness of consumer-generated advertising. J. Advert. 42, 4, 292-307 (2013).

18. Lee, M. et al.: Effects of valence and extremity of eWOM on attitude toward the brand and website. J. Curr. Issues Res. Advert. 31, 2, 1-11 (2009).

19. Li, M. et al.: Helpfulness of online product reviews as seen by consumers: Source and content features. Int. J. Electron. Commer. 17, 4, 101-136 (2013).

20. Lim, B.C., Chung, C.M.Y.: The impact of word-of-mouth communication on attribute evaluation. J. Bus. Res. 64, 1, 18-23 (2011).

21. Liu, F. et al.: Deciphering Individuals' Preference for User Generated Content: Effects of Personality on Users' Processing of Online Review Information. In: Proceedings of the 36th International Conference on Information Systems (ICIS 2015), Fort Worth, Texas, December 13 - 16. (2015).

22. Macrae, C.N., Bodenhausen, G. V: Social cognition: Categorical person perception. Br. J. Psychol. 92, 1, 239-255 (2001).

23. McKnight, D.H. et al.: Developing and validating trust measures for e-commerce: an integrative typology. Inf. Syst. Res. 13, 3, 334-359 (2002).

24. Moore, G., Benbasat, I.: Development of an instrument to measure the perceptions of adopting an information technology innovation. Inf. Syst. Res. (1991).

25. Mudambi, S.M., Schuff, D.: What Makes a Helpful Online Review? A Study of Customer Reviews on Amazon.com. MIS Q. 34, 1, 185-200 (2010).

26. Munier, B. et al.: Bounded Rationality Modeling. Mark. Lett. 10, 3, 233-248 (1999).

27. Nadkarni, S., Gupta, R.: A task-based model of web site complexity. MIS Q. 31, 3, 501-524 (2007).

28. Nunnally, J.C., Bernstein, I.H.: Psychometric theory. New York McGraw-Hill. (1994).

29. Park, D.H., Kim, S.: The effects of consumer knowledge on message processing of electronic word-of-mouth via online consumer reviews. Electron. Commer. Res. Appl. 7, 4, 399-410 (2008).

30. Park, D.H., Lee, J.: eWOM overload and its effect on consumer behavioral intention depending on consumer involvement. Electron. Commer. Res. Appl. 7, 4, 386-398 (2008).

31. Racherla, P. et al.: Factors affecting consumers' trust in online product reviews. J. Consum. Behav. 11, 2, 94-104 (2012).

32. Reb, J., Connolly, T.: The effects of action, normality, and decision carefulness on anticipated regret: Evidence for a broad mediating role of decision justifiability. Cogn. Emot. 24, 8, 1405-1420 (2010).

33. Salehan, M., Kim, D.J.: Predicting the performance of online consumer reviews: A sentiment mining approach to big data analytics. Decis. Support Syst. 81, 30-40 (2016).

34. Schriesheim, C.A.: The similarity of individual directed and group directed leader behavior descriptions. Acad. Manag. J. 22, 2, 345-355 (1979). 
35. Simon, H.A.: Rational decision making in business organizations. Am. Econ. Rev. 493-513 (1979).

36. Simon, H.A.: The information-processing theory of mind. Am. Psychol. 50, 7, 507 (1995).

37. Sparks, B.A., Browning, V.: The impact of online reviews on hotel booking intentions and perception of trust. Tour. Manag. 32, 6, 1310-1323 (2011).

38. Thompson, D. V, Malaviya, P.: Consumer-generated ads: Does awareness of advertising cocreation help or hurt persuasion? J. Mark. 77, 3, 33-47 (2013).

39. Wixom, B.B.H., Watson, H.J.: An empirical investigation of the factors affecting data warehousing success. MIS Q. 25, 1, 17-41 (2001).

40. Xia, L., Bechwati, N.N.: Word of mouse: The role of cognitive personalization in online consumer reviews. J. Interact. Advert. 9, 1, 3-13 (2008).

41. Yang, J., Mai, E.S.: Experiential goods with network externalities effects: An empirical study of online rating system. J. Bus. Res. 63, 9, 1050-1057 (2010).

42. Zadeh, L.A. et al.: Fuzzy Sets and Their Applications to Cognitive and Decision Processes: Proceedings of the US-Japan Seminar on Fuzzy Sets and Their Applications, Held at the University of California, Berkeley, California, July 1-4, 1974. Academic Press (2014).

43. Zhu, L. et al.: Is this opinion leader's review useful? Peripheral cues for online review helpfulness. J. Electron. Commer. Res. 15, 4, 267 (2014). 